\title{
Treatment of Childhood Oppositional Defiant Disorder
}

\author{
Bradley S. Hood, $M D^{1, *}$ \\ Marilisa G. Elrod, MD, PhD ${ }^{2}$ \\ David B. DeWine, PhD
}

\author{
Address \\ *,1Developmental Services, Mary Bridge Children's, 1220 Division Ave., Tacoma, \\ WA 98403, USA \\ Email: brad.hood@multicare.org \\ ${ }^{2}$ Department of Developmental-Behavioral Pediatrics, Madigan Army Medical Center, \\ Joint Base Lewis McChord, Tacoma, WA 98431, USA \\ ${ }^{3}$ Pediatric Psychology \& Psychiatry Service, Mary Bridge Children's, 1220 Division \\ Ave., Tacoma, WA 98403, USA
}

Published online: 3 April 2015

(C) Springer International Publishing AG 2015

\section{This article is part of the Topical Collection on General Pediatrics}

Keywords Oppositional defiant disorder - Attention-deficit hyperactivity disorder - Parent management training • Disruptive behavior disorders

\section{Opinion statement}

Oppositional defiant disorder (ODD) is a common behavioral disorder of childhood which can be described as a learned pattern of behavior reinforced by caregivers' responses. Behavioral modification for ODD, particularly in preschool and school-aged children, should primarily focus on teaching caregivers to reinforce positive behaviors, discourage negative behaviors, and ultimately interrupt the cycle of argumentativeness and deliberate attention-seeking behavior. Unfortunately, children who are referred for behavioral therapy for ODD often do not receive evidence-based treatments that target the root cause of the disorder. There is some role for the use of psychopharmacology in the treatment of $\mathrm{ODD}$, though primarily in the treatment of underlying and comorbid disorders. The core symptoms of ODD are not amenable to pharmacotherapy, and behavioral modification is the mainstay of intervention. Attention-deficit hyperactivity disorder (ADHD) frequently occurs with ODD. Poor impulse control is a core feature of ADHD, and appropriate use of stimulant and/or non-stimulant ADHD medications can help children with ODD make better behavioral choices and be more successful with behavior modification programs. There is some evidence for the effectiveness of atypical antipsychotics in disruptive behavior disorders (DBDs), but the target symptoms of explosive and aggressive behaviors are seen only in children with more severe ODD who progress to conduct disorder (CD). Pediatric providers should understand the evidence-based behavioral interventions and targeted psychiatric medications that will achieve the best outcomes for children with ODD. 


\section{Case}

You are seeing a previously healthy 4 -year-old William in your office for behavior problems at preschool and at home. This is the third preschool he has attended after having been asked to leave his prior two for out of control behavior. His mother reports that he refuses to comply with her directions and will argue with her when confronted. He frequently is involved in physical altercations in his preschool class. He tells his teacher at school and his mother that they are "stupid" and that he hates them. His mother has brought William in today because she feels that she is at her "wit's end" and his teacher thinks "he needs to be medicated." Vanderbilt scales from his mother and teacher indicate attention-deficit hyperactivity disorder, combined inattentive, and hyperactive type. You note that the oppositional defiant disorder (ODD) screen is

positive for both mother and teacher. On further discussion, his mother states that she and William's father are divorced and that they differ significantly in their parenting styles. She admits she has mostly "given up" on correcting her son's behavior, but his father is extremely strict and "on him all the time." You discuss the importance of consistent parenting with the mother and recommend that the child and both parents establish care with a mental health professional for Parent Management Training (PMT). You also provide recommendations for parenting books. You discuss with William's mother that you would consider starting a stimulant attention-deficit hyperactivity disorder (ADHD) medication if behavioral interventions do not improve his functioning and plan to see him back in 3 months.

\section{Introduction}

ODD is a pattern of negative behavior and interaction characterized by an angry or irritable mood, argumentative or defiant behavior, and vindictiveness. In the Diagnostic and Statistical Manual of Mental Disorders-Fifth Edition (DSM-5), it is contained in the Disruptive, Impulse-Control, and Conduct Disorders section, grouped with intermittent explosive disorder, conduct disorder (CD), antisocial personality disorder, pyromania, and kleptomania $[1 \bullet \bullet]$. According to DSM-5 diagnostic criteria, symptoms must last at least 6 months and be exhibited during interaction with a non-sibling as evidenced by at least four symptoms from any of following: loses temper, is touchy or easily annoyed, is angry and resentful, argues with authority figures, actively defies or refuses to comply with requests from authority figures or with rules, deliberately annoys others, blames others for his or her mistakes or misbehavior, or has been spiteful or vindictive at least twice within the past 6 months. These must be seen often and more frequently than would be typically observed in children of comparable age and developmental level. Behaviors must impair function in at least one setting and not be better explained by other diagnoses.

In the Diagnostic and Statistical Manual of Mental Disorders-Fourth Edition (DSM-IV), ODD had been grouped with the disruptive behavior disorders (DBDs) that included Attention-Deficit/Hyperactivity Disorder (ADHD) and CD [2]. Changes from the DSM-IV criteria in the new DSM-5 include removal of the exclusion criteria for $\mathrm{CD}$ and guidance on frequency of symptoms to reflect developmental expectations. Description of the core behaviors is unchanged. All research presented in this article is based on the DSM-IV criteria.

Estimates based on DSM-IV criteria show a lifetime prevalence of ODD of $11.3 \%$ [3]. Onset of symptoms is typically in the preschool years with an 
average age of onset of 4 years of age and rarely after early adolescence [1 $\bullet \bullet, 3]$. It is more prevalent in males than in females (1:1.4) prior to adolescence. Early onset of ODD results in slow recovery, although up to $70 \%$ of childhood cases do resolve by adulthood. ODD is associated with later development of secondary psychiatric disorders including mood disorders, impulse control disorders, and drug abuse. Lifetime comorbidity of other mental disorders in those with ODD has been estimated at $92.4 \%$ [3]. Oppositional behaviors at 47 years also predict conduct problems at 8-13 years [4]. ODD is the most common psychiatric comorbidity in children with ADHD, seen in up to $60 \%$ of these children [5].

ODD is a leading cause of referral for youth mental health services. While prior clinical approaches conceptualized ODD as the prodrome of CD, ODD has been determined to be its own entity and has independent associations with future mental health issues [6]. Those with defiant, argumentative, and vindictive symptoms are most at risk for developing CD. Those with angryirritable mood symptoms are most likely to go on to develop anxiety disorders and major depressive disorder $[1 \bullet \bullet]$.

Psychosocial dysfunction has been implicated in the development of ODD. It is associated with harsh, inconsistent, or neglectful parenting practices, and is also seen more frequently in children who have had their child care disrupted by a succession of different caregivers $[1 \bullet \bullet, 5]$. There is also evidence that neurobiological factors increase the risk of developing a DBD. Markers associated with ODD include lower heart rate and skin conductance reactivity, reduced basal ganglia reactivity, and abnormalities in the prefrontal cortex and amygdala [6].

Treatment of ODD should be focused on non-pharmacologic approaches as psychopharmacology is relatively ineffective for the core symptoms of ODD. Pharmacologic management should be viewed as adjunctive for the treatment of comorbid ADHD [7]. Research on pharmacological treatment of ODD has often combined CD and ODD into a single group, confounding results. Study populations typically have included mostly male children. Improvement related to medication effects is only seen during the treatment period and does not persist once medications are stopped, and all medications come with the risk of side effects.

\section{Treatment}

\section{Behavioral treatment}

ODD is one of the most common behavioral health conditions presenting in pediatric primary care clinics. Parents frequently question whether their child's defiance is developmentally appropriate or excessive and request help in managing their child's disruptive behavior. Diagnosis and treatment are often timeconsuming and require collaboration with collateral colleagues (teachers, mental health professionals, coaches) which can be a challenge within a busy primary care setting. However, given the risk for worsening problems children with ODD face, and the scarcity of mental health services in many communities, pediatricians should be familiar with the most effective treatments for this condition.

Primary prevention is the optimum strategy and can be part of pediatric well-child visits [7]. Researchers have found screening children as young as 
12 months can accurately identify youth at risk of disruptive behavior in early childhood [8], and simple, effective screening tools are readily available (http:// www2.massgeneral.org/schoolpsychiatry/screeningtools_table.asp). Once the diagnosis has been made, there are a number of evidence-based psychosocial treatments that can effectively improve behavioral problems and foster family functioning.

First-line treatments for ODD are behavioral family therapies. Medications should only be used as adjunctive treatments for severe or treatment-resistant children. The most common approach to treating ODD is a group of therapies collectively referred to as Parent Management Training (PMT). These interventions are based on the early work of Gerald Patterson and his colleagues who viewed ODD as a pattern of learned behaviors fostered by reciprocal negative interactions between a child and her parent(s) [9]. The PMT approaches utilize operant conditioning strategies (e.g., the use of rewards and punishments to shape voluntary behaviors) to foster positive parent/child relationships, increase adaptive behaviors, and reduce disruptive or non-compliant behaviors.

Clinicians typically teach parents to be clear with their commands, to remain consistent with expectations and consequences, to reward positive behaviors, and ignore negative attention-seeking behaviors from their children. The clinician models positive parenting techniques with the child and coaches the parent to increase his or her confidence. Research on PMT consistently demonstrates effectiveness in managing oppositional behaviors, reducing parental stress, and improving family cohesion [10]. For the most part, clinician-led PMT interventions will incorporate both parent and child training which have been found to be more effective than providing training to parents or children alone [11].

Elizabeth Webster-Stratton's Incredible Years [12], Robert McMahon and Rex Forehand's Noncompliant Child Training [13], Sheila Eyberg's Parent-child Interaction Therapy [14], and Russell Barkley's Defiant Teens intervention [15] are all commonly utilized PMTs. These programs are typically provided by mental health professionals in an outpatient setting, but adaptations to schools [16] and primary care clinics [17 $\bullet$ ] have been successful. These programs typically require 10-14 and 60-90 min sessions, which is a significant commitment for many families and often leads to high attrition rates [18].

While it is clear these therapies are effective, research has found they are not always superior to less intensive approaches amenable to the primary care setting [19]. For example, nurse or counselor-led [20] brief PMTs and selfguided parenting materials (bibliotherapy) $[16,19,21,22]$ have been shown to be as effective as moderately intense PMT's (less than eight sessions) and offer a more practical option in a busy primary care setting [18].

An alternative evidence-based approach to management of ODD is Collaborative Problem Solving (CPS) or Collaborative and Proactive Solutions [23]. CPS is a parent-based intervention that approaches the disorder from a different perspective than PMT. CPS views childhood and adolescent defiance as the result of a youth's lagging executive skills. CPS seeks to train emotionally reactive and inflexible youth to regulate their emotions, tolerate frustration, and solve problems more effectively. CPS is taught to parents, teachers, and counselors who then utilize the model in the context in which the youth is struggling. While clinical research on this approach is limited to one published clinical trial comparing CPS to PMT, it was comparably effective in reducing oppositional 
defiance and parental stress [24]. The model is widely disseminated in the popular press for parents [25•] and teachers [26] although no studies of its effectiveness as a self-guided bibliotherapy have been published.

Parenting books including Ross Greene's E xplosive Child: A new approach for understanding and parenting easily frustrated, "chronically inflexible" children [25•], Thomas Phelan's 1,2,3 Magic: Effective Discipline for Children 2-12 [21], and Lynn Clark's SOS Help for Parents [22] provide parents with sound evidencebased recommendations for managing ODD at home. Given the amount of time and energy formal therapies often require, and the evidence suggesting bibliotherapy can be an effective level of intervention for many families, recommending appropriate parenting materials and offering parents consultation to reinforce learning are recommended in the context of primary care.

Individual counseling and treatment approaches to ODD such as cognitive behavioral therapy have been less effective than family- and school-based approaches but should be considered for children with comorbid anxiety or mood problems $[10,27]$. Finally, intense inoculation or aversion therapies (e.g., "Scared Straight" [28]) are not recommended as effective treatments for ODD or disruptive behavior disorders. Studies examining the effectiveness of these programs have found them to be ineffective and potentially harmful to youth [29]. See Table 1 for a summary of non-pharmacologic treatments for childhood ODD.

\section{Case-continued}

William and his mother return to your office 2 years later. His mother reports that her son's behavior initially improved with PMT, but he has continued to have problems at home and at school. He continues to argue with adults, blames others for his misbehavior, and deliberately annoys his classmates at school. He is not able to pay attention in school and will often leave his seat during instruction. Getting out of the house in the morning takes $90 \mathrm{~min}$ as he will not follow directions or forgets what he has been asked to do. You diagnose William with ADHD and comorbid ODD and start him on methylphenidate. You recommend continued PMT.

Medications are used as adjuncts to treat ADHD symptoms which may exacerbate ODD or aggression that may accompany ODD. Many pharmacological studies are confounded as they combine subjects with ODD and CD into a single group with the assumption that ODD represents a less severe or prodromal form of CD. Also, the outcome measure for effectiveness of medications for ODD is most commonly aggression which may be associated with ODD but is not a diagnostic criterion. Ideally, children with ADHD and ODD should be treated with monotherapy with the initial choice of a stimulant medication. Other medications with varying amounts of evidence to support efficacy for the treatment of oppositional symptoms in children with ODD include clonidine, guanfacine, atomoxetine, and risperidone. Most treatment effects of oppositional symptoms are highly correlated with those of ADHD core symptoms, making it difficult to independently assess the effectiveness of medications for 


\section{Table 1. Behavioral therapies for oppositional behavioral disorder}

Interventions provided by mental health professionals

Program

Parent Management Training (PMT)

- Incredible years [12]

- Noncompliant Child Training [13]

- Parent-child Interaction Therapy [14]

- Defiant Teens Intervention [15]

Collaborative Problem Solving [23]

Cognitive behavioral therapy

Available options for primary care settings

Nurse or counselor-led brief PMTs

Parenting Books

- The Explosive Child: A new approach to parenting easily frustrated, "chronically inflexible" children [25]

- 1,2,3 Magic: Effective Discipline for Children 2-12 [21]

- SOS Help for Parents [22]
Comments

Use rewards and punishments to shape voluntary behaviors to foster positive parent/child relationships, increase adaptive behaviors, and reduce disruptive or non-compliant behaviors

Trains emotionally reactive and inflexible youth to regulate their emotions, tolerate frustration, and solve problems more effectively

Less effective than family and school-based approaches but should be considered for children with comorbid anxiety or mood problems

Have been shown to be as effective as moderately intense PMT and offer a more practical option in A busy primary care setting

ODD [30, 31]. See Table 2 for a summary of pharmacologic treatments.

There has been a trend to add an atypical neuroleptic to a stimulant medication in the setting of poor response to monotherapy and severe aggression. This particular practice of polypharmacy for the treatment of child aggression

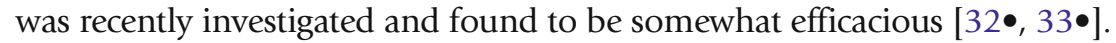
However, it is recommended that severely aggressive children with ODD be referred for management by a child psychiatrist.

Stimulants are the most widely studied medications for ADHD and generally felt to be most effective in children with ODD for treatment of core ADHD symptoms. A meta-analysis of the effects of stimulant medications on overt aggression (which included ODD) in children with ADHD found that there was a moderate to large effect (effect size $=0.84 ; 95 \%$ confidence interval $(\mathrm{CI})$, $0.696,1.024 ; p$ value $<0.001$ ) in reducing aggressive behaviors. However, this meta-analysis also revealed a significant variability in outcome among studies not accounted for by factors measured in the analysis and also included children with ODD and CD along with other aggressive behaviors into a single group [34].

Methylphenidate (MPH) has been shown to reduce ODD symptoms in children with ADHD in several studies [35-38]. However, the benefits were more widely reported on teacher rating scales than on parental rating scales. This may represent the negativity that can accompany a close long-term relationship colored by ODD. There are no recommendations that can be made as 


\begin{tabular}{|c|c|c|c|}
\hline & Members of class & Potential side effects & Efficacy \\
\hline $\begin{array}{l}\text { Stimulant } \\
\text { medications }\end{array}$ & $\begin{array}{l}\text { Methylphenidate, mixed } \\
\text { amphetamine salts, } \\
\text { d-amphetamine, } \\
\text { lisdexamfetamine }\end{array}$ & $\begin{array}{l}\text { Abdominal pain, trouble sleeping, } \\
\text { loss of appetite, headache }\end{array}$ & $\begin{array}{l}\text { Effective in reducing oppositional } \\
\text { symptoms in children with } \\
\text { comorbid ADHD }\end{array}$ \\
\hline $\begin{array}{l}\text { Alpha-2 } \\
\text { agonists }\end{array}$ & Guanfacine, clonidine & $\begin{array}{l}\text { Somnolence, headache, } \\
\text { sedation, fatigue, and } \\
\text { upper abdominal pain, } \\
\text { modest changes in blood } \\
\text { pressure, and pulse rate, } \\
\text { PR elongation on ECG }\end{array}$ & $\begin{array}{l}\text { Limited data, but some evidence } \\
\text { that they may reduce oppositional } \\
\text { symptoms in children with ADHD }\end{array}$ \\
\hline $\begin{array}{l}\text { Selective } \\
\text { norepinephrine } \\
\text { reuptake } \\
\text { inhibitor }\end{array}$ & Atomoxetine & $\begin{array}{l}\text { Loss of appetite, nausea } \\
\text { and/or vomiting, dyspepsia, } \\
\text { fatigue and/or weakness, } \\
\text { increased transaminases } \\
\text { and acute liver failure in } \\
\text { rare cases }\end{array}$ & $\begin{array}{l}\text { Effective in reducing oppositional } \\
\text { symptoms in children with } \\
\text { comorbid ADHD }\end{array}$ \\
\hline $\begin{array}{l}\text { Atypical } \\
\text { neuroleptics }\end{array}$ & $\begin{array}{l}\text { Risperidone, } \\
\text { aripiprazole, } \\
\text { quetiapine }\end{array}$ & $\begin{array}{l}\text { Acute and chronic extrapyramidal } \\
\text { neurological symptoms, } \\
\text { increased appetite, } \\
\text { hyperglycemia, hyperlipidemia, } \\
\text { and hypertriglyceridemia, } \\
\text { hyperprolactinemia }\end{array}$ & $\begin{array}{l}\text { Effective in reducing aggressive and } \\
\text { disruptive behaviors in children } \\
\text { with below normal intellectual } \\
\text { functioning. Some evidence that } \\
\text { they are effective in reducing } \\
\text { oppositional symptoms in children } \\
\text { with ADHD and aggressive or } \\
\text { disruptive behaviors }\end{array}$ \\
\hline
\end{tabular}

to the most efficacious form of MPH (immediate release vs. extended release systems) for oppositional symptoms as no direct comparisons have been made. However, one recent study describes the benefit of careful titration of once-daily $\mathrm{MPH}$ combined with behaviorally oriented psychosocial treatment for the target behavior of aggression in children with ADHD, comorbid ODD or CD, and a history of insufficient response to stimulants [39]. The authors claim that progression to the addition of atypical neuroleptics may be prevented by careful titration of MPH monotherapy.

There has been one randomized, double-blind, placebo-controlled trial of mixed amphetamine salts (MAS) that compared children with ADHD and ODD to those with ODD alone. This study found that oppositional symptoms improved in children with ADHD and ODD for a specific dosage of $30 \mathrm{mg} /$ dose/day of extended release MAS. However, for the children with ODD only, there was no significant change in parental rating scores [40]. Another study showed similar effects of MAS on disruptive and antisocial behaviors in children with ADHD [38]. The aforementioned meta-analysis found no difference between MPH and MAS for the treatment of aggressive-related behaviors in children with ADHD [34].

The most common treatment-emergent adverse events (TEAEs) for MPH have been reported as abdominal pain, trouble sleeping, and loss of appetite $[36,38]$. The most common TEAEs for MAS were reported as anorexia/ 
decreased appetite, insomnia, headache, abdominal pain, and weight loss. No significant ECG or heart rate changes were noted [40].

\section{Alpha-2 agonists}

Clonidine and guanfacine are $\alpha-2$ agonists shown to be effective for the treatment of ADHD. These medications are U.S. Food and Drug Administration (FDA) approved as monotherapy and adjuncts for children with ADHD with suboptimal response to stimulant monotherapy. In practice, they are most commonly used as ADHD monotherapy in children with side effects to stimulant medications, and occasionally as first-line agents in predominantly hyperactive children. There are very limited data on their effectiveness in specifically addressing oppositional symptoms.

A pilot study that compared MPH, MPH with clonidine, and clonidine alone for the treatment of children with ADHD with aggressive oppositional behaviors showed a benefit for all three therapies compared to baseline, but no difference among the three treatment arms was detected [41]. A recent meta-analysis of the effects of $\alpha-2$ agonists as monotherapy and in combination therapy for ADHD (without formal diagnosis of ODD) examined reduction of oppositional symptoms as a secondary outcome measure. However, only two studies (one clonidine immediate release and one guanfacine extended release) met the inclusion criteria [30, 42]. The pooled standardized mean difference for oppositional symptoms was -0.44 (95\% CI, $-0.69,-0.20 ; p<0.001)$ [43•]. Another study, not included in the meta-analysis, demonstrated improvement of impulsive, oppositional, and defiant behaviors with MPH but not clonidine [44].

There is little research on $\alpha-2$ agonists as adjuncts to stimulants for the reduction of oppositional symptoms for children diagnosed with both ADHD and ODD. A single study found a reduction in parent-reported conduct symptoms for clonidine as an adjunct to a stimulant in children with ADHD and ODD [45].

The most commonly reported adverse events for the $\alpha$-2 agonists are somnolence, headache, sedation, fatigue, and upper abdominal pain. These effects are usually transient with resolution within 6 to 8 weeks [30, 46]. As $\alpha-2$ agonists are also antihypertensive medications, there are also modest changes in blood pressure, pulse rate, and PR elongation on ECG [30].

Atomoxetine (ATX) is a selective norepinephrine reuptake inhibitor that is approved for the treatment of ADHD in adults and children 6 years of age and older. Similar to the $\alpha-2$ agonists, ATX is a non-stimulant medication that is primarily used in children with ADHD who cannot tolerate or do not respond optimally to stimulant medications. Unlike stimulants and $\alpha-2$ agonists, ATX is dosed by weight. Also dissimilar to stimulant therapy, it may take up to 8 weeks to see the full therapeutic effect of ATX.

A recent meta-analysis demonstrated that ATX was equivalent to MPH in reducing ADHD symptoms in children with ADHD and comorbid ODD, but did not specifically address effects on oppositionality [47•]. Another metaanalysis of children with ADHD showed a significant reduction in oppositional/defiant symptoms for ATX vs. placebo, but the effect was less robust than the improvement in ADHD symptoms. Oppositional/defiant symptoms improved similarly in both comorbid ADHD/ODD subjects and 
non-comorbid (subthreshold) ADHD subjects, and the authors concluded that the improvement in oppositional/defiant behavior was secondary to ATX's effect on ADHD [48].

One often-referenced study demonstrated improvement in both ADHD and ODD symptoms, but higher doses of ATX $(1.8 \mathrm{mg} / \mathrm{kg} / \mathrm{day})$ were required to reduce ADHD symptoms in subjects with comorbid ODD vs. those without $(1.2 \mathrm{mg} / \mathrm{kg} /$ day) [31]. Other studies have concluded that decreases in oppositionality are highly correlated to the magnitude of improvement in core ADHD symptoms. ATX has been shown to reduce ADHD symptoms in children with and without ODD, and the presence of oppositional symptoms does not appear to affect the rate of relapse of ADHD symptoms. ATX may improve treatment of ODD indirectly through control of ADHD symptoms. Similarly, the presence of ODD symptoms is associated with an increased severity of ADHD. But the preponderance of evidence does not support a primary effect of ATX on oppositionality $[49,50]$.

The most commonly reported adverse effects for ATX include loss of appetite, nausea and/or vomiting, dyspepsia, and fatigue and/or weakness [48]. ATX has been associated with increased transaminases and acute liver failure in rare cases. It should be discontinued immediately in the case of jaundice or elevation of hepatic enzymes [51]. ATX's chemical structure is similar to that of a selective serotonin reuptake inhibitor (SSRI), and it carries a boxed warning regarding the risk of suicidal ideation in children and adolescents.

The atypical antipsychotics risperidone and aripiprazole are currently approved by the FDA for use in children and adolescents only for irritability associated with autism and for bipolar disorder. Other medications in this class are not currently approved for use in children. Data from the 1995-2010 National Ambulatory Medical Care Surveys revealed that antipsychotics were the fastest growing class of psychotropic medications in the pediatric population and that much of the increase in antipsychotic use in children and adolescents was for the treatment of DBDs, including ODD in spite of the fact that antipsychotics are not generally considered a first-line treatment for these conditions due to safety concerns. It was also noted that antipsychotic prescriptions from non-

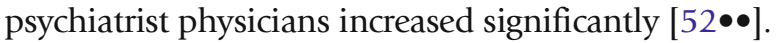

The majority of research regarding the use of atypical antipsychotics for DBDs has focused on targeting aggressive behaviors, which are much more specific to CD than to ADHD/ODD. Many studies have also focused on children with both cognitive disabilities and disruptive behaviors, which is a distinct population from typically developing children with ADHD and co-

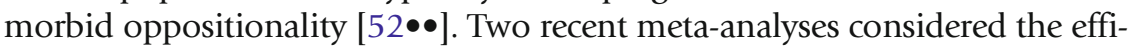
cacy of atypical antipsychotics in treating DBDs. There is evidence of benefit for the use of risperidone in youth with subaverage IQ and disruptive behaviors. However, there was relatively weak evidence supporting the use of atypical antipsychotics in youth with average IQ and aggression and conduct problems $[52 \bullet \bullet, 53 \bullet \bullet]$. Conclusions were limited by heterogeneity of the study populations which included children with low IQ, but in general, the concurrent use of psychostimulants and psychosocial interventions is not adequately addressed

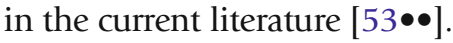


There is some evidence that in children with ADHD and ODD who are not responding to parent training and optimized stimulant therapy, risperidone

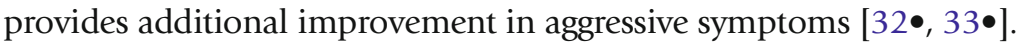

The most commonly reported adverse effects for antipsychotic medications is significant increase in appetite resulting in overweight or obesity. Antipsychotics can cause metabolic side effects and extrapyramidal symptoms. Children should be routinely monitored for involuntary movements utilizing a tool such as the Abnormal Involuntary Movement Scale (AIMS) [54, 55].

\section{Other medications}

Lithium and first-generation antipsychotic medications have been shown to decrease aggressive behaviors in hospitalized children. Carbamazepine is frequently prescribed as a mood stabilizer, but has not been found to be superior to placebo in treating $\mathrm{CD}$ [56]. There is no clear role for these medications in the treatment of ADHD/ODD, particularly in the absence of aggressive behavior, and consultation with child psychiatry is recommended for their use in the treatment of disruptive behavior disorders.

\section{Case-conclusion}

William and his mother return to your office for an ADHD follow-up visit 6 months later. Follow-up Vanderbilt scales indicate that his ADHD symptoms are relatively well controlled on his current dosage of methylphenidate, but he is still exhibiting symptoms of ODD. His mother admits that she and William's father had struggled to find common ground regarding parenting techniques and stopped attending PMT sessions. You stress the importance of continued support from a mental health provider for behavioral management in conjunction with medication as their son is at risk for developing $\mathrm{CD}$ in the future. You also screen for depression and anxiety and recommend monitoring for mood and anxiety symptoms at future well-child visits.

\section{Compliance with Ethics Guidelines}

\section{Conflict of Interest}

Bradley S. Hood declares that he has no conflict of interest.

Marilisa G. Elrod declares that she has no conflict of interest.

David B. DeWine declares that he has no conflict of interest.

Human and Animal Rights and Informed Consent

This article does not contain any studies with human or animal subjects performed by any of the authors.

\section{Disclaimer}

The views expressed are those of the authors and do not reflect the official policy of the Department of the Army, the Department of the Navy, the Department of Defense, or the US Government. 


\section{References and Recommended Reading}

Papers of particular interest, published recently, have been

highlighted as:

- Of importance

$\bullet$ Of major importance

1.• American Psychiatric Association, Diagnostic and statistical manual of mental disorders (5th ed.). 2013, Washington, DC: Author.

This is the 2013 revision of the American Psychiatric Association's criteria for the diagnosis and classification of mental disorders. In the United States it serves as the authoritative reference.

2. American Psychiatric Association, Diagnostic and statistical manual of mental disorders (4th ed., text rev.). 2000, Washington, DC: Author.

3. Nock MK et al. Lifetime prevalence, correlates, and persistence of oppositional defiant disorder: results from the National Comorbidity Survey Replication. J Child Psychol Psychiatry. 2007;48(7):703-13.

4. Lahey BB et al. Are oppositional-defiant and hyperactive-inattentive symptoms developmental precursors to conduct problems in late childhood?: Genetic and environmental links. J Abnorm Child Psychol. 2009;37(1):45-58.

5. Connor DF, Steeber J, McBurnett K. A review of attention-deficit/hyperactivity disorder complicated by symptoms of oppositional defiant disorder or conduct disorder. J Dev Behav Pediatr. 2010;31(5):427-40.

6. Stadler C, Poustka F, Sterzer P. The heterogeneity of disruptive behavior disorders - implications for neurobiological research and treatment. Front Psychiatry. 2010;1:21.

7. Steiner H, Remsing L. Work Group on Quality Issues, Practice parameter for the assessment and treatment of children and adolescents with oppositional defiant disorder. J. Am. Acad. Child Adolesc. Psychiatry, 2007. 46(1).

8. Briggs-Gowan MJ, Carter AS. Social-emotional screening status in early childhood predicts elementary school outcomes. Pediatrics. 2008;121(5):957-62.

9. Patterson GR. Living with children: new methods for parents and teachers (revised). Champaign: Research Press; 1977.

10. Brestan EV, Eyberg SM. Effective psychosocial treatments of conduct-disordered children and adolescents: 29 years, 82 studies, and 5,272 kids. J Clin Child Psychol. 1998;27(2):180-9.

11. Webster-Stratton $\mathrm{C}$, Hammond $\mathrm{M}$. Treating children with early-onset conduct problems: a comparison of child and parent training interventions. J Consult Clin Psychol. 1997;65(1):93.

12. Webster-Stratton C. The incredible years: parent, teacher, and child training series (IYS). In: Preventing violence and related health-risking social behaviors in adolescents: An NIH State-of-the-Science Conference. 2011.
13. McMahon RJ, Forehand RL. Helping the noncompliant child: family-based treatment for oppositional behavior. New York: Guilford Press; 2005.

14. Zisser A, Eyberg SM. Treating oppositional behavior in children using parent-child interaction therapy. In: Weisz JR, Kazdin AE, editors. Evidence-based psychotherapies for children and adolescents. New York: Guilford Press; 2010. p. 179-93.

15. Barkley RA, Edwards GH, Robin AL. Defiant teens: a clinician's manual for assessment and family intervention. New York: Guilford Press; 1999.

16. Webster-Stratton C, Reid MJ, Hammond M. Treating children with early-onset conduct problems: intervention outcomes for parent, child, and teacher training. J Clin Child Adolesc Psychol. 2004;33(1):105-24.

17.• Perrin EC et al. Improving parenting skills for families of young children in pediatric settings: a randomized clinical trial. JAMA Pediatr. 2014;168(1):16-24.

This study examined the effectiveness of a 10 week parent training group provided in a primary care setting. Groups were offered to parents of young children and the results were positive, supporting PC Parent Training to prevent future disruptive behaviors.

18. Lavigne JV et al. Predictors and correlates of completing behavioral parent training for the treatment of oppositional defiant disorder in pediatric primary care. Behav Ther. 2010;41(2):198-211.

19. Lavigne JV et al. Treating oppositional defiant disorder in primary care: a comparison of three models. J Pediatr Psychol. 2008;33(5):449-61.

20. Turner KM, Sanders MR. Help when it's needed first: a controlled evaluation of brief, preventive behavioral family intervention in a primary care setting. Behav Ther. 2006;37(2):131-42.

21. Phelan T. 1-2-3 magic: effective discipline for children 2-12. 5th ed. Glen Ellyn: ParentMagic, Inc.; 2014.

22. Clark L. SOS Help for parents: a practical guide for handling common everyday behavior problems. 2005: SOS Programs \& Parents Pres.

23. Greene RW, Ablon JS. Treating explosive kids: the collaborative problem-solving approach. New York: Guilford Press; 2005.

24. Greene RW et al. Effectiveness of collaborative problem solving in affectively dysregulated children with oppositional-defiant disorder: initial findings. J Consult Clin Psychol. 2004;72(6):1157.

25. Greene RW, The explosive child: a new approach for understanding and parenting easily frustrated, "chronically inflexible" Children. 5th ed. Children. 2014, New York: Harper Collins.

This book outlines the research, theory and method behind 
Dr. Greene's approach to working with oppositional and emotionally explosive children and adolescents. His approach aims to reduce emotional deregulation in children by teaching collaborative problem solving and communication skills.

26. Greene RW. Lost at school: why our kids with behavioral challenges are falling through the cracks and how we can help them. New York: Simon and Schuster; 2009.

27. Burke JD, Loeber R, Birmaher B. Oppositional defiant disorder and conduct disorder: a review of the past 10 years, part II. J Am Acad Child Adolesc Psychiatry. 2002;41(11):1275-93.

28. Shapiro, A., Scared Straight! (Motion Picture). 1978, Pyramid Films: Santa Monica, CA

29. Connor DF. Aggression and antisocial behavior in children and adolescents: research and treatment. New York: Guilford Press; 2002.

30. Connor DF et al. Effects of guanfacine extended release on oppositional symptoms in children aged 6-12 years with attention-deficit hyperactivity disorder and oppositional symptoms. CNS Drugs. 2010;24(9):755-68.

31. Newcorn JH et al. Atomoxetine treatment in children and adolescents with attention-deficit/hyperactivity disorder and comorbid oppositional defiant disorder. J Am Acad Child Adolesc Psychiatry. 2005;44(3):240-8.

32. Gadow KD et al. Risperidone added to parent training and stimulant medication: effects on attention-deficit/ hyperactivity disorder, oppositional defiant disorder, conduct disorder, and peer aggression. J Am Acad Child Adolesc Psychiatry. 2014;53(9):948-959.e1.

This study compared the efficacy of parent training and stimulant medication plus placebo versus risperidone on $\mathrm{ADHD}$, ODD, and CD symptoms. Risperdone reduced the severity of ADHD and ODD symptoms, peer aggression, and impairment, but effect sizes ranged from small to moderate.

33. Aman MG et al. What does risperidone add to parent training and stimulant for severe aggression in child attention-deficit/hyperactivity disorder? J Am Acad Child Adolesc Psychiatry. 2014;53(1):47-60.e1.

This study investigated the addition of risperidone to concurrent psychostimulant and parent training for children with severe aggression. Risperidone provided moderate but variable improvement in aggressive and seriously disruptive child behaviors.

34. Connor DF et al. Psychopharmacology and aggression. I: a meta-analysis of stimulant effects on overt/covert aggression-related behaviors in ADHD. J Am Acad Child Adolesc Psychiatry. 2002;41(3):253-61.

35. Gadow KD et al. Methylphenidate in children with oppositional defiant disorder and both comorbid chronic multiple tic disorder and ADHD. J Child Neurol. 2008;23(9):981-90.

36. Schachar RJ et al. Behavioral, situational, and temporal effects of treatment of ADHD with methylphenidate. J Am Acad Child Adolesc Psychiatry. 1997;36(6):754-63.

37. van der Oord $\mathrm{S}$ et al. Does brief, clinically based, intensive multimodal behavior therapy enhance the effects of methylphenidate in children with ADHD? Eur Child Adolesc Psychiatry. 2007;16(1):48-57.
38. Pelham WE et al. A comparison of ritalin and adderall: efficacy and time-course in children with attentiondeficit/hyperactivity disorder. Pediatrics. 1999;103(4):e43.

39. Blader JC et al. Stimulant-responsive and stimulantrefractory aggressive behavior among children with ADHD. Pediatrics. 2010;126(4):e796-806.

40. Spencer TJ et al. Efficacy and safety of mixed amphetamine salts extended release (adderall XR) in the management of oppositional defiant disorder with or without comorbid attention-deficit/hyperactivity disorder in school-aged children and adolescents: a 4week, multicenter, randomized, double-blind, parallelgroup, placebo-controlled, forced-dose-escalation study. Clin Ther. 2006;28(3):402-18.

41. Connor DF, Barkley RA, Davis HT. A pilot study of methylphenidate, clonidine, or the combination in ADHD comorbid with aggressive oppositional defiant or conduct disorder. Clin Pediatr. 2000;39(1):15-25.

42. Tourette's Syndrome Study Group. Treatment of ADHD in children with tics: a randomized controlled trial. Neurology. 2002;58(4):527-36.

43. Hirota T, Schwartz S, Correll CU. Alpha-2 agonists for attention-deficit/hyperactivity disorder in youth: a systematic review and meta-analysis of monotherapy and add-on trials to stimulant therapy. J Am Acad Child Adolesc Psychiatry. 2014;53(2):153-73.

This meta-analysis of the effects of $\alpha-2$ agonists as therapy for ADHD showed moderate reduction in oppositional symptoms based on the two studies that met inclusion criteria for this secondary outcome measure.

44. Palumbo DR et al. Clonidine for attention-deficit/hyperactivity disorder: I. Efficacy and tolerability outcomes. J Am Acad Child Adolesc Psychiatry.

2008;47(2):180-8.

45. Hazell PL, Stuart JE. A randomized controlled trial of clonidine added to psychostimulant medication for hyperactive and aggressive children. J Am Acad Child Adolesc Psychiatry. 2003;42(8):886-94.

46. Daviss WB et al. Clonidine for attention-deficit/hyperactivity disorder: II. ECG changes and adverse events analysis. J Am Acad Child Adolesc Psychiatry. 2008;47(2):189-98.

47. van Wyk GW et al. How oppositionality, inattention, and hyperactivity affect response to atomoxetine versus methylphenidate: a pooled meta-analysis. J Atten Disord. 2012;16(4):314-24.

This meta-analysis assessed how threshold ODD, inattention, and hyperactivity-impulsivity affect the response to atomoxetine versus methylphenidate. ADHD symptom response was equivalent between the two. Meeting the threshold criteria for ODD, inattention, or hyperactivity-impulsivity did not alter the response.

48. Schwartz S, Correll CU. Efficacy and safety of atomoxetine in children and adolescents with attention-deficit/hyperactivity disorder: results from a comprehensive meta-analysis and metaregression. J Am Acad Child Adolesc Psychiatry. 2014;53(2):17487. 
49. Biederman J et al. Effect of comorbid symptoms of oppositional defiant disorder on responses to atomoxetine in children with ADHD: a meta-analysis of controlled clinical trial data. Psychopharmacol (Berl). 2007;190(1):31-41.

50. Hazell $P$ et al. Comorbid oppositional defiant disorder and the risk of relapse during 9 months of atomoxetine treatment for attention-deficit/hyperactivity disorder. Eur Child Adolesc Psychiatry. 2006;15(2):105-10.

51. United States National Library of Medicine, The National Institute of Diabetes and Digestive and Kidney Diseases, LiverTox Drug Record: Atomoxetine. 2014.

52.• Pringsheim T, Gorman D. Second-generation antipsychotics for the treatment of disruptive behaviour disorders in children: a systematic review. Can J Psychiatry. 2012;57(12):722-7.

This meta-analysis investigated efficacy of second-generation antipsychotic use in youth. Four studies support the short-term efficacy of low-dose risperidone in youth with subaverage IQ and disruptive behaviors. Placebo-controlled evidence was found to be weak or nonexistent for SGAs other than risperidone, and weak in youth with average IQ.
53.• Loy JH et al. Atypical antipsychotics for disruptive behaviour disorders in children and youths. Cochrane Database Syst Rev. 2012;9:Cd008559.

This meta-analysis included seven randomised controlled trials assessing risperidone and one assessing quetiapine for efficacy in aggression and conduct problems. There was limited evidence of the efficacy of risperidone in reducing aggression and conduct problems.

54. Pringsheim T et al. Metabolic and neurological complications of second-generation antipsychotic use in children: a systematic review and meta-analysis of randomized controlled trials. Drug Saf.

2011;34(8):651-68.

55. Pringsheim T et al. Evidence-based recommendations for monitoring safety of second-generation antipsychotics in children and youth. Paediatr Child Health. 2011;16(9):581-9.

56. Kutcher S et al. International consensus statement on attention-deficit/hyperactivity disorder (ADHD) and disruptive behaviour disorders (DBDs): clinical implications and treatment practice suggestions. Eur Neuropsychopharmacol. 2004;14(1):11-28. 